\title{
Perspective-Current Understanding of the Halogenated Deposition Chemistry for Chemical Vapor Deposition of SiC
}

Henrik Pedersen, Lars Ojamäe and Örjan Danielsson

The self-archived postprint version of this journal article is available at Linköping University Institutional Repository (DiVA):

http://urn.kb.se/resolve?urn=urn:nbn:se:liu:diva-171381

N.B.: When citing this work, cite the original publication.

Pedersen, H., Ojamäe, L., Danielsson, Ö., (2020), Perspective-Current Understanding of the

Halogenated Deposition Chemistry for Chemical Vapor Deposition of SiC, ECS Journal of Solid State

Science and Technology, 9(10), 104006. https://doi.org/10.1149/2162-8777/abbf2e

Original publication available at:

https://doi.org/10.1149/2162-8777/abbf2e

Copyright: Electrochemical Society

http://www.electrochem.org/ 


\title{
Current understanding of the halogenated deposition chemistry for chemical vapor deposition of $\mathrm{SiC}$
}

Henrik Pedersen ${ }^{z}$, Lars Ojamäe, Örjan Danielsson

Department of Physics, Chemistry and Biology, Linköping University, SE-581 83 Linköping, Sweden

Corresponding Author: henrik.pedersen@liu.se

\begin{abstract}
The deposition rate of silicon carbide ( $\mathrm{SiC}$ ) in chemical vapor deposition (CVD) can be boosted by addition of chlorine. This has been explored and applied for hard coatings and electronic grade SiC. We briefly summarize the recent research done in the field of SiC CVD and discuss the understanding of the CVD chemistry with addition of halides. We seek to improve a previous statement that $\mathrm{SiCl}_{2}$ is the main silicon species for growth of $\mathrm{SiC}$. Recent experiments and modeling suggest that $\mathrm{SiCl}_{2}$, and its fluorinated and brominated analogues, are inactive and that $\mathrm{SiF} / \mathrm{SiCl} / \mathrm{SiBr}$ are the main halogenated species for growth.
\end{abstract}

\section{Introduction}

Silicon carbide $(\mathrm{SiC})$ is both a hard material and a wide bandgap semiconductor with high thermal conductivity. This has made it a very interesting material for power electronics as well as hard coatings, both applications require film deposition. The preferred method for depositing thin films of SiC is chemical vapor deposition (CVD). While CVD of SiC for hard coatings applications typically use the single-source precursor methyl trichlorosilane, $\mathrm{CH}_{3} \mathrm{SiCl}_{3}$ (MTS), ${ }^{1} \mathrm{CVD}$ of electronic grade $\mathrm{SiC}$ typically uses silane, $\mathrm{SiH}_{4}$, and either ethylene, $\mathrm{C}_{2} \mathrm{H}_{4}$, or propane, $\mathrm{C}_{3} \mathrm{H}_{8}$, as precursors with a possibility to vary the $\mathrm{C} / \mathrm{Si}$ ratio in the gas mixture. ${ }^{2}$ In both cases, the precursors are diluted in a carrier gas; the hard coatings industry often uses nitrogen for low cost and safety, while the electronics industry uses hydrogen since nitrogen is a n-type dopant in SiC. CVD of SiC for hard coatings is typically done at $1000-1400{ }^{\circ} \mathrm{C}^{1}$ while CVD for epitaxial SiC films require higher temperatures of 
$1500-1700{ }^{\circ} \mathrm{C} .^{2}$

Motivated by the need for thick, 50-200 $\mu$ m epitaxial layers for power device applications, ${ }^{3}$ there has been considerable research efforts during the past 15-20 years to use a chlorinated CVD chemistry also for electronic grade $\mathrm{SiC}$. CVD of $\mathrm{SiC}$ using $\mathrm{SiH}_{4}$ and $\mathrm{C}_{2} \mathrm{H}_{4} / \mathrm{C}_{3} \mathrm{H}_{8}$ could 20 years ago only afford growth rates of $5-10 \mu \mathrm{m} / \mathrm{h} .{ }^{4}$ The deposition was here limited by the low partial pressure of $\mathrm{SiH}_{4}$ possible in the process; too high partial pressure of $\mathrm{SiH}_{4}$ resulted in homogeneous gas phase nucleation of silicon droplets, detrimental to the $\mathrm{SiC}$ surface morphology making the epitaxial layer useless for device fabrication. The addition of an excess of $\mathrm{Cl}$ to the CVD chemistry prevents the formation of $\mathrm{Si}-\mathrm{Si}$ bonds (bond enthalpy 226 $\mathrm{kJ} \mathrm{mol}^{-1}$ or $\left.2.34 \mathrm{eV}\right)^{5}$ since the stronger $\mathrm{Si}-\mathrm{Cl}$ bonds (bond enthalpy $400 \mathrm{~kJ} \mathrm{~mol}^{-1}$ or $4.15 \mathrm{eV}$ ) are thermodynamically more favored. The use of chlorinated CVD chemistry affords deposition rates for epitaxial SiC films of $100-200 \mu \mathrm{m} / \mathrm{h}^{6}$

We reviewed the field of chlorinated CVD chemistry for electronic grade $\mathrm{SiC} 2012^{6}$ and discussed then the understanding of the CVD chemistry up to that point in time. The research in the field has since then expanded to include also fluorinated and brominated CVD chemistry for epitaxial SiC films. ${ }^{7,8}$ These works and more detailed modelling of the chlorinated CVD chemistry for SiC has shifted our understanding of the chemical mechanisms in halogenated CVD of SiC. In this paper we therefore summarize the current understanding of halogenated CVD chemistry for SiC and point out the need for more detailed modeling in CVD coupled with careful experiments for a better understanding of CVD chemistry in general.

\section{Current Status}

In our 2012 review we drew the conclusion that $\mathrm{SiCl}_{2}$ is the most important species for the deposition of $\mathrm{SiC}$, i.e. the major silicon species contributing to growth of $\mathrm{SiC} .^{6}$ This was based on the result that it was always the Si species with the highest concentration in the gas phase in all thermochemical models; regardless of the chemical approach to chlorinated CVD chemistry, i.e. if chlorinated silanes, chlorinated hydrocarbons, MTS or HCl-addition was used for a chlorinated CVD chemistry. This was also analogous to the current understanding that $\mathrm{SiH}_{2}$ is the most important species in standard, non-chlorinated, CVD chemistry for 
electronic grade $\mathrm{SiC}$. We also argued for using the formation path of $\mathrm{SiCl}_{2}$ from the precursor molecules as a guide to understand the differences in precursor utilization between the approaches to chlorinated CVD chemistry: The lower growth rate for the same amount of precursor supplied for the approach to use $\mathrm{SiH}_{4}$ with added $\mathrm{HCl}$ compared to $\mathrm{HSiCl}_{3}$ could be explained by a less complicated chemical path to form $\mathrm{SiCl}_{2}$ from $\mathrm{HSiCl}_{3}$ compared to $\mathrm{SiH}_{4}+$ $2 \mathrm{HCl}^{9}$

\section{Signs that the importance of $\mathrm{SiCl}_{2}$ was insufficient}

Encouraged by early results comparing MTS with the brominated analogue methyl tribromosilane, $\mathrm{CH}_{3} \mathrm{SiBr}_{3}$ (MTBS) showing a higher deposition rate and lower activation energy of epitaxial SiC from MTBS compared to MTS, ${ }^{10}$ we did a direct comparison between brominated and chlorinated CVD chemistry for $\mathrm{SiC}$ by adding either $\mathrm{HBr}$ or $\mathrm{HCl}$ to $\mathrm{SiH}_{4}$ and $\mathrm{C}_{2} \mathrm{H}_{4}{ }^{7}$ The $\mathrm{Si}-\mathrm{Br}$ bond has a bond enthalpy of $330 \mathrm{~kJ} \mathrm{~mol}^{-1}$ or $3.42 \mathrm{eV}$. We showed reproducibility of the higher deposition rate for a brominated chemistry compared to a chlorinated chemistry. When we did thermochemical modeling to compare the brominated and chlorinated chemistries, we found that the brominated analogue to $\mathrm{SiCl}_{2}, \mathrm{SiBr}_{2}$, was formed in lower amounts than $\mathrm{SiCl}_{2}$. This was a puzzling result as it was expected that the higher observed deposition rate of $\mathrm{SiC}$ with addition of $\mathrm{HBr}$, compared to addition of $\mathrm{HCl}$, should be explained by a higher concentration of $\mathrm{SiBr}_{2}$, compared to $\mathrm{SiCl}_{2}$. We therefore concluded that the understanding of the importance for $\mathrm{SiCl}_{2}$, then expanded also to $\mathrm{SiBr}_{2}$, was likely insufficient. ${ }^{7}$ That is, the major Si containing gas species is inactive for the growth of $\mathrm{SiC}$.

In parallel we started quantum chemical modeling of the surface chemistry of SiC CVD, studying the differences between $\mathrm{SiH}_{2}$ and $\mathrm{SiCl}_{2}$ to probe the origins of the higher deposition rate afforded with a chlorinated chemistry. ${ }^{11}$ It was expected that the $\mathrm{SiCl}_{2}$ species should have a more favorable surface chemistry compared to the $\mathrm{SiH}_{2}$ species to explain the tenfold increase in deposition rate with a chlorinated CVD chemistry. We found that the $\mathrm{SiH}_{2}$ species had a higher adsorption energy and lower activation energy for adsorption compared to $\mathrm{SiCl}_{2} .{ }^{11} \mathrm{SiH}_{2}$ was also found to diffuse more easily on the $\mathrm{SiC}$ surface than $\mathrm{SiCl}_{2} .{ }^{11}$ These results did not support the experimental results that the chlorinated CVD chemistry gives a 
higher deposition rate. When this modeling was extended to also include $\mathrm{SiBr}_{2}$, it was found that the difference in adsorption energies between $\mathrm{SiCl}_{2}$ and $\mathrm{SiBr}_{2}$ on the $\mathrm{SiC}$ surface is very small, ${ }^{7}$ which does not support the experimental observations that brominated CVD chemistry gives higher deposition rate than chlorinated CVD chemistry.

To complete the investigations of the halogens in SiC CVD we undertook studies of fluorinated CVD chemistry using $\mathrm{SiF}_{4}$. We demonstrated that $\mathrm{SiF}_{4}$ can be used for CVD of epitaxial SiC films, but the deposition rate achieved were only about $30 \mu \mathrm{m} / \mathrm{h} .{ }^{8}$ This can be expected from the bond enthalpy, the very strong Si-F bonds $\left(597 \mathrm{~kJ} \mathrm{~mol}^{-1} \text { or } 6.19 \mathrm{eV}\right)^{5}$ should render a much slower kinetics resulting in fewer growth species. Through combined thermochemical modeling and careful experiments, we showed that the fluorinated $\mathrm{SiCl}_{2}$ analogue, $\mathrm{SiF}_{2}$, cannot be a growth species, but instead $\mathrm{SiF}$ is likely the main growth species, possibly with minor contributions from $\mathrm{SiHF}^{8}$

\section{Future Needs and Prospects}

\section{A better understanding through better modeling}

The concentration of gas phase species above the surface is not the only factor of importance for the deposition chemistry. We have recently described a systematic modeling approach for CVD that combine quantum chemical calculations with computational fluid dynamics for multi scale modeling of CVD processes. ${ }^{12}$ In short, the approach is a seven step protocol where the controlling phenomena/factors are identified through a system and time scale analysis and a model for the gas phase reaction mechanisms and determine reaction rate constants utilizing quantum-chemical computations or other methods is constructed. The gas phase kinetic model is verified by performing gas phase kinetics simulations and species concentration trends are evaluated from the kinetic model and compare with experiments to determine growth species. A surface reaction mechanism is then constructed and used to determine reaction rate constants. Computational Fluid Dynamics (CFD) is then used to simulate the CVD process with the gas phase and surface kinetics included. Finally the CFD model is validated against experiments. In this modeling approach, the reaction kinetics were modelled taking both concentrations and reaction free energy barriers into account. The latter case often using the Eyring formula (which leads to the Arrhenius equation). For the details 
of the calculations, we refer to $\mathrm{Ref}^{12}$.To demonstrate this modeling approach, we used $\mathrm{SiC}$ as a model system and deduced a detailed chemical model for CVD of SiC without using correction factors to fit experimental data. The model can explain several phenomena in CVD of epitaxial SiC:

The amount of surface-active carbon species controls the nitrogen doping in $\mathrm{SiC} .{ }^{13}$ It is known that the nitrogen doping does not vary much with temperature between $1500-1600{ }^{\circ} \mathrm{C} .{ }^{14}$ Our recent modeling shows that the concentrations of $\mathrm{C}_{2} \mathrm{H}_{2}$ and $\mathrm{CH}_{3}$ remain constant between $1400-1700^{\circ} \mathrm{C}$, while $\mathrm{CH}_{4}$ and $\mathrm{C}_{2} \mathrm{H}_{4}$ decrease.

When varying the concentrations of carbon, i.e. the $\mathrm{C} / \mathrm{Si}$ ratio, species with more than two silicon atoms (silicon clusters) decrease with increasing $\mathrm{C} / \mathrm{Si}$, while species with more than three carbon atoms increases to significant levels. The degree of step bunching can be controlled by changing the $\mathrm{C} / \mathrm{Si}$ ratio, and it is suggested that step bunching is caused by either Si or C clusters on the surface. ${ }^{15}$ The modeling results support the presence of such species at these conditions.

A rough surface is an indication of high carbon concentrations (high C/Si ratio), and experiments show that high $\mathrm{Si} / \mathrm{H}_{2}$ requires lower input $\mathrm{C} / \mathrm{Si}$ to maintain a $\mathrm{SiC}$ film with smooth morphology. ${ }^{16}$ With increasing silicon concentrations (high $\mathrm{Si} / \mathrm{H}_{2}$, maintaining C/Si ratio), a saturation in growth rate, along with a roughening of the surface is observed experimentally. ${ }^{17}$ This indicates that at some Si concentration level, species that do not contribute to the growth are formed instead of the growth species. Modeling results show concentration saturations of $\mathrm{Si}, \mathrm{SiH}$, and $\mathrm{SiH}_{2}$ above $\mathrm{Si} / \mathrm{H}_{2}=0.1 \% . \mathrm{SiCl}$ and $\mathrm{SiBr}$ increase at least up to $\mathrm{Si} / \mathrm{H}_{2}=1.0 \%$, and concentrations level out beyond $\mathrm{Si} / \mathrm{H}_{2}>1.0 \%$, while $\mathrm{SiF}$ (and $\mathrm{SiHF}$ ) remain constant at $\mathrm{Si} / \mathrm{H} 2>0.05 \%$. In the standard $\mathrm{Si}-\mathrm{C}-\mathrm{H}$ system, larger Si-containing species (clusters) are formed instead of the smaller active growth species. In the chlorine and bromine cases, some of the silicon goes to forming the clusters, and some form halogenated silicon species, which reduces the amount of gas phase nucleation. In the fluorine case, the silicon goes almost exclusively to $\mathrm{SiF}_{2}$ and $\mathrm{SiF}_{4-\mathrm{n}} \mathrm{H}_{\mathrm{n}}(\mathrm{n}=0-3)$.

The model also shows that $\mathrm{SiCl}_{2}$ is not a species active for growth since the concentration of $\mathrm{SiCl}_{2}$ increases with higher $\mathrm{Cl} / \mathrm{Si}$ ratio in the inlet CVD gas mixture and decreases with increasing temperature while the experimental deposition rates show opposite trends. ${ }^{18,19}$ 
Using the same modeling approach for brominated and fluorinated chemistries in CVD of $\mathrm{SiC}$, we also see lower concentrations of $\mathrm{Si}-\mathrm{Br}$ species as compared to $\mathrm{Si}-\mathrm{Cl}$ species and higher concentrations of $\mathrm{Si}-\mathrm{C}$ and $\mathrm{Si}-\mathrm{H}$ species in the $\mathrm{Br}$ chemistry as compared to $\mathrm{Cl}$. Since the growth rate is about $10 \%$ higher using the $\mathrm{Br}$ chemistry, ${ }^{7}$ this would indicate that the halogenated species do not have a positive effect on the growth rate. In the fluorinated chemistry, the concentrations of $\mathrm{Si}-\mathrm{C}$ and $\mathrm{Si}-\mathrm{H}$ species are at least one order of magnitude lower, as compared to the other chemistries. This could indicate that there are fewer number of different active growth species in the F chemistry, and we speculate that this could lead to fewer structural defects.

The current understanding of halogenated CVD chemistry for SiC

Gas phase chemistry

The high temperatures used for CVD of electronic grade SiC ensures that chemical equilibrium establishes faster than the residence time for the gas in the reactor. Since the residence time, i.e. the time the gas spends in the deposition zone of the CVD reactor, is of the order of $0.1-1.0 \mathrm{~s}$, this means that the highly reactive radicals that are created have enough time to react and form more stable species. Therefore, we could expect that species with high concentrations at thermodynamic equilibrium will also be present in relatively high concentrations in the SiC CVD reactor, even though concentration levels may be different. Therefore, we use the approach to analyzing changes in concentrations of the high-concentration species at equilibrium with different modelled process conditions to get an idea of the behavior of the chemistry involved, which helps us building a kinetic reaction model with all the relevant reaction paths.

It is then concluded that species with concentrations high enough to provide sufficient material to $\mathrm{SiC}$ deposition are: $\mathrm{CH}_{3}, \mathrm{CH}_{4}, \mathrm{C}_{2} \mathrm{H}_{2}, \mathrm{C}_{2} \mathrm{H}_{4}, \mathrm{Si}, \mathrm{SiH}_{2}, \mathrm{Si}_{2} \mathrm{C}, \mathrm{Si}_{3} \mathrm{C}, \mathrm{SiCH}_{2}, \mathrm{SiC}_{2}$, $\mathrm{SiCl}_{2}, \mathrm{SiCl}, \mathrm{SiHCl}$ (or the corresponding $\mathrm{Br}$ and $\mathrm{F}$ species). Some of these species are more stable than others and will therefore not contribute to the deposition of SiC.

In previous literature, species with the highest concentrations were automatically assumed to be the ones contributing to the growth. Therefore, $\mathrm{SiCl}_{2}$ was expected to contribute the most to the growth of $\mathrm{SiC} .{ }^{6}$ Following the same reasoning, $\mathrm{SiBr}_{2}$ and $\mathrm{SiF}_{2}$ would contribute the 
most when chlorine is substituted for bromine or fluorine. However, the growth rate is higher when using bromine compared to chlorine, while it is lower when using fluorine. ${ }^{7,8}$ Here, we present modeling of the gas phase chemistry using the systematic modeling method for $\mathrm{CVD}^{12}$. These results show an opposite trend of the relative $\mathrm{SiX}_{2}$ concentrations, both with temperature (Fig. 1) and with increasing halogen to silicon ratio in the gas mixture (Fig. 2). As explained above, the difference in adsorption rates is too small to account for the difference in growth rates.

Another noteworthy approach to an increased understanding of the CVD chemistry for deposition of $\mathrm{SiC}$ is the study by Shima et al. ${ }^{20}$ where high aspect ratio structures combined with mass spectrometry was used to reveal the importance of the $\mathrm{CH}_{2} \mathrm{SiCl}_{3}$ species when using the common precursor methyl trichlorosilane, $\mathrm{CH}_{3} \mathrm{SiCl}_{3}$ (MTS).

\section{Surface chemistry}

During CVD, dangling bonds on the SiC surface will, to a large extent, be passivated. Deposition of $\mathrm{SiC}$ is suggested to be highly dependent on the creation of vacancies, i.e. sites with dangling bonds in the surface passivation layer. ${ }^{21}$ For the standard, non-halogenated CVD chemistry, the surface will be passivated by hydrogen atoms. In halogenated CVD chemistry, halogen atoms are also available for surface passivation. Given the high bond enthalpy of halogens-silicon and halogen-carbon, it is not surprising that halogenated CVD chemistry renders a lower probability to form vacancies in the surface passivating layer. ${ }^{22}$ For example, in Ref. ${ }^{22}$ it was found that the surface Si dangling bond ratio fell from about 0.75 to about 0.3 when the $\mathrm{F} / \mathrm{H}_{2}$ ratio was increased from 0 to $0.5 \%$ at typical CVD conditions, based on first-principles calculations. The $\mathrm{SiC}$ deposition can to some extent be regarded as inhibited by the presence of halogen atoms on the surface. This explains the often observed decrease in deposition rate with higher halogen to silicon ratio in the inlet CVD gas mixture; higher partial pressure of halogen atoms in the gas phase lowers the probability to form vacancies in the surface passivating layer which hinders the deposition of SiC. We argue that this surface passivating effect is more probable to explain the reduction in deposition rate with higher partial pressure of halogen, than the often-suggested increased competing etching of the $\mathrm{SiC}$ film. In addition, the etching efficiency of $\mathrm{HCl}$ molecules were computationally 
found to be subpar as compared to that of $\mathrm{H}$ atoms, which of course are present in both halogenated and non-halogenated CVD. ${ }^{23}$

A recent paper by Rana et al. found a route to graphene synthesis on $\mathrm{SiC}$ by a surface treatment by $\mathrm{SiF}_{4}$ where the $\mathrm{SiF}_{4}$ is suggested to etch $\mathrm{Si}$ from the $\mathrm{SiC}$ surface. ${ }^{24}$ One must remember that the surface passivation that we discuss is, like any atomic layer at temperatures above $1000{ }^{\circ} \mathrm{C}$ dynamic - it will lose atoms, forming vacancies and new atoms will arrive to the surface to fill the vacancies. If one does not provide the chemical species for material growth, as in the study by Rana et al, etching of surface silicon will be significant. It is important to note that in the study by Rana et al. they etch away silicon to form graphene one does not need a high etching rate to remove one to two atomic layers of silicon in a minute. If the drop in deposition rate seen when using $\mathrm{SiF}_{4}$ as $\mathrm{Si}$-precursor is going to be explained only by a higher etching rate, then the etching rate must be in the order of $70 \mu \mathrm{m} / \mathrm{h}$ and would also require the etching of carbon. The adsorption process on the silicon face of $\mathrm{SiC}$ by precursors such as $\mathrm{Si}, \mathrm{SiH}, \mathrm{SiH}_{2}, \mathrm{SiHX}$ and $\mathrm{SiX}_{2}$ have been investigated by quantum-chemical calculations. ${ }^{25}$ It was found that the adsorption had the highest adsorption energy at methylene sites, where it occurs without activation energy barriers. Comparing Hand $\mathrm{Cl}$-chemistries, the most favorable (i.e. lowest) reaction Gibbs free energy was for $\mathrm{Si}$ adsorption, followed by $\mathrm{SiH}, \mathrm{SiCl}, \mathrm{SiH}_{2}, \mathrm{SiHCl}$ and $\mathrm{SiCl}_{2}$. Looking at $\mathrm{F}$ - and $\mathrm{Br}$-chemistries, the internal ordering was $\mathrm{SiX}, \mathrm{SiHX}$ and $\mathrm{SiX}_{2}$. Similar results were prior obtained for $\mathrm{F}$ in Ref. ${ }^{8}$. This indicates that the most potent Si contributors to the growth process are the species $\mathrm{Si}, \mathrm{SiHX}$ and $\mathrm{SiH}$. Plausible reaction mechanisms for bulk formation starting from $\mathrm{SiH}$ respective $\mathrm{SiCl}$ were also investigated, and it can be noted that for the reaction step with the highest energy barrier the Gibbs free activation energy was 309 and $269 \mathrm{~kJ} / \mathrm{mol}$, respectively, indicating $\mathrm{SiCl}$ to be kinetically favored over $\mathrm{SiH}$.

The surface reaction scheme from Ref. ${ }^{25}$ was used in the microkinetic simulation segment of the CFD simulations of CVD growth using $\mathrm{SiH}_{4}$ and $\mathrm{C}_{2} \mathrm{H}_{4}$ as precursors in Ref. ${ }^{12}$. Si and $\mathrm{SiH}$ as silicon precursors was found to be sufficient to reproduce the experimentally observed growth rate, which at the very least shows that it is possible that $\mathrm{SiH}$ is one of the most important growth species. Further and more extensive studies are needed in order to unambiguously predict the dominant growth species from simulations alone. Such studies 
should also include edge and terrace effects. A systematic and thorough scanning of more of the multitude of possible reaction paths together with sensitivity analyses for the computed growth rates would be desirable, possibly using machine learning tools.

\section{Conclusions}

In this paper we have tried to update our understanding of chlorinated CVD chemistry of SiC from ten years ago and in doing that give a fuller description of the chemistry in the CVD process. We briefly review more recent results to point out that our former understanding with the $\mathrm{SiCl}_{2}$ species as the most important species for deposition of $\mathrm{SiC}$ is insufficient. Recent modeling suggests this, the major Si containing gas phase species, to be inactive for the deposition and rather function as a gas phase reservoir for Si. Instead, recent findings point towards $\mathrm{SiCl}$ as the most important $\mathrm{Si}$ species for $\mathrm{SiC}$ deposition with $\mathrm{C}_{2} \mathrm{H}_{2}$ as the most important $\mathrm{C}$ species. These results also extend to fluorinated and brominated CVD of SiC. Recent findings also point to a change in surface chemistry in halogenated CVD compared to standard CVD where the SiC surface is believed to be halogen terminated rather than hydrogen terminated, posing an alternative explanation than enhanced etching for the decrease in deposition rate with higher halogen to Si ratio.

\section{Acknowledgments}

We wish to express our gratitude to Milan Yazdanfar, Pitsiri Sukkaew, Pontus Stenberg and Emil Kalered for their hard work on various aspects of halogenated CVD of $\mathrm{SiC}$, as $\mathrm{PhD}$ students under our supervision. We are also very grateful for financial support from the Knut \& Alice Wallenberg Foundation through the project "Isotopic Control for Ultimate Material Properties", the Swedish Foundation for Strategic Research (SSF) through the project "SiC the Material for Energy-Saving Power Electronics" (EM11-0034), the Swedish Research Council (VR) and the Advanced Functional Materials center (AFM) at Linköping University. Supercomputing resources for this work were provided by the Swedish National Infrastructure for Computing (SNIC) and the Swedish National Supercomputer Centre (NSC). 


\section{References}

${ }^{1}$ K.L. Choy, Prog. Mater. Sci. 48, 57 (2003).

${ }^{2}$ O. Kordina, C. Hallin, A. Henry, J.P. Bergman, I.G. Ivanov, A. Ellison, N.T. Son, and E. Janzén, Phys. Status Solidi 202, 321 (1997).

${ }^{3}$ J.A. Cooper and A. Agarwal, Proc. IEEE 90, 956 (2002).

${ }^{4}$ A.A. Burk, Chem. Vap. Depos. 12, 465 (2006).

${ }^{5}$ W.M. Haynes, editor, CRC Handbook of Chemistry and Physics, 97th ed. (CRC Press Tylor \& Francis Group, Boca Raton London New York, 2016).

${ }^{6}$ H. Pedersen, S. Leone, O. Kordina, A. Henry, S.-I. Nishizawa, Y. Koshka, and E. Janzén, Chem. Rev. 112, 2434 (2012).

${ }^{7}$ M. Yazdanfar, Ö. Danielsson, E. Kalered, P. Sukkaew, O. Kordina, D. Nilsson, I.G. Ivanov, L. Ojamäe, E. Janzén, and H. Pedersen, Chem. Mater. 27, 793 (2015).

${ }^{8}$ P. Stenberg, P. Sukkaew, I. Farkas, O. Kordina, E. Janzén, L. Ojamäe, Ö. Danielsson, and H. Pedersen, J. Phys. Chem. C 121, 2711 (2017).

${ }^{9}$ M. Yazdanfar, O. Danielsson, O. Kordina, E. Janzen, and H. Pedersen, ECS J. Solid State Sci. Technol. 3, P320 (2014).

${ }^{10}$ T. Kunstmann, H. Angerer, J. Knecht, and S. Vepřek, Chem. Mater. 7, 1675 (1995).

${ }^{11}$ E. Kalered, H. Pedersen, E. Janzén, and L. Ojamäe, Theor. Chem. Acc. 132, 1403 (2013).

12 Ö. Danielsson, M. Karlsson, P. Sukkaew, H. Pedersen, and L. Ojamäe, J. Phys. Chem. C 124, 7725 (2020).

${ }^{13}$ D.J. Larkin, P.G. Neudeck, J.A. Powell, and L.G. Matus, Appl. Phys. Lett. 65, 1659 (1994).

${ }^{14}$ U. Forsberg, Ö. Danielsson, A. Henry, M.. Linnarsson, and E. Janzén, J. Cryst. Growth 236, 101 (2002).

${ }^{15}$ Y. Ishida, T. Takahashi, H. Okumura, K. Arai, and S. Yoshida, Mater. Sci. Forum 600-603, 473 (2008)

${ }^{16}$ F. La Via, G. Izzo, M. Camarda, G. Abbondanza, and D. Crippa, Mater. Sci. Forum 615-617, 55 (2009).

17 T. Tanaka, N. Kawabata, Y. Mitani, M. Sakai, N. Tomita, M. Tarutani, T. Kuroiwa, Y. Toyoda, M. Imaizumi, H. Sumitani, and S. Yamakawa, Mater. Sci. Forum 821-823, 133 (2015). 
${ }^{18}$ S. Leone, F.C. Beyer, H. Pedersen, S. Andersson, O. Kordina, A. Henry, and E. Janzén, Thin Solid Films 519, 3074 (2011).

${ }^{19}$ R. Karhu, I. Booker, J. Ul Hassan, I. Ivanov, and E. Janzén, Mater. Sci. Forum 821-823, $141(2015)$.

${ }^{20}$ K. Shima, N. Sato, Y. Funato, Y. Fukushima, T. Momose, and Y. Shimogaki, ECS J. Solid State Sci. Technol. 8, P423 (2019).

${ }^{21}$ P. Sukkaew, Ö. Danielsson, O. Kordina, E. Janzén, and L. Ojamäe, J. Phys. Chem. C 121, 1249 (2017).

${ }^{22}$ P. Stenberg, Ö. Danielsson, E. Erdtman, P. Sukkaew, L. Ojamäe, E. Janzén, and H. Pedersen, J. Mater. Chem. C 5, 5818 (2017).

${ }^{23}$ P. Sukkaew, Ö. Danielsson, and L. Ojamäe, J. Phys. Chem. A 122, 2503 (2018).

${ }^{24}$ T. Rana, M.V.S. Chandrashekhar, K. Daniels, and T. Sudarshan, Jpn. J. Appl. Phys. 54, 030304 (2015).

${ }^{25}$ P. Sukkaew, E. Kalered, E. Janzén, O. Kordina, Ö. Danielsson, and L. Ojamäe, J. Phys. Chem. C 122, 648 (2018). 


\section{Figures and Figure Captions}

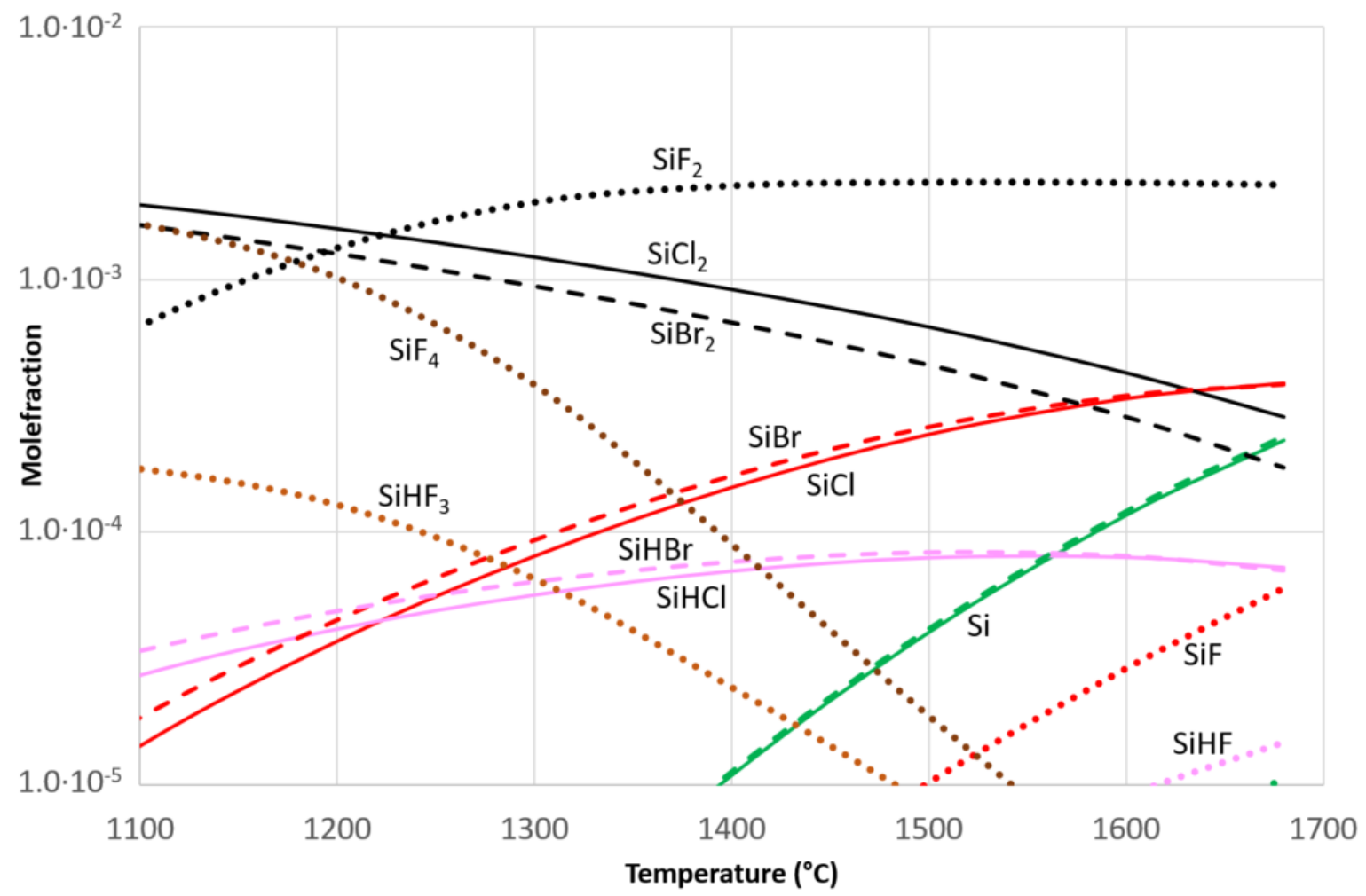

Fig. 1 Molefractions of halogenated silicon species at equilibrium when varying the temperature $(\mathrm{Si} / \mathrm{H} 2=0.25 \%, \mathrm{C} / \mathrm{Si}=1.0, \mathrm{X} / \mathrm{Si}=4.0$ where $\mathrm{X}=\mathrm{Cl}, \mathrm{Br}$ or $\mathrm{F})$. Solid lines represent a chlorinated CVD chemistry, dashed lines a brominated CVD chemistry and dotted lines a fluorinated CVD chemistry. 


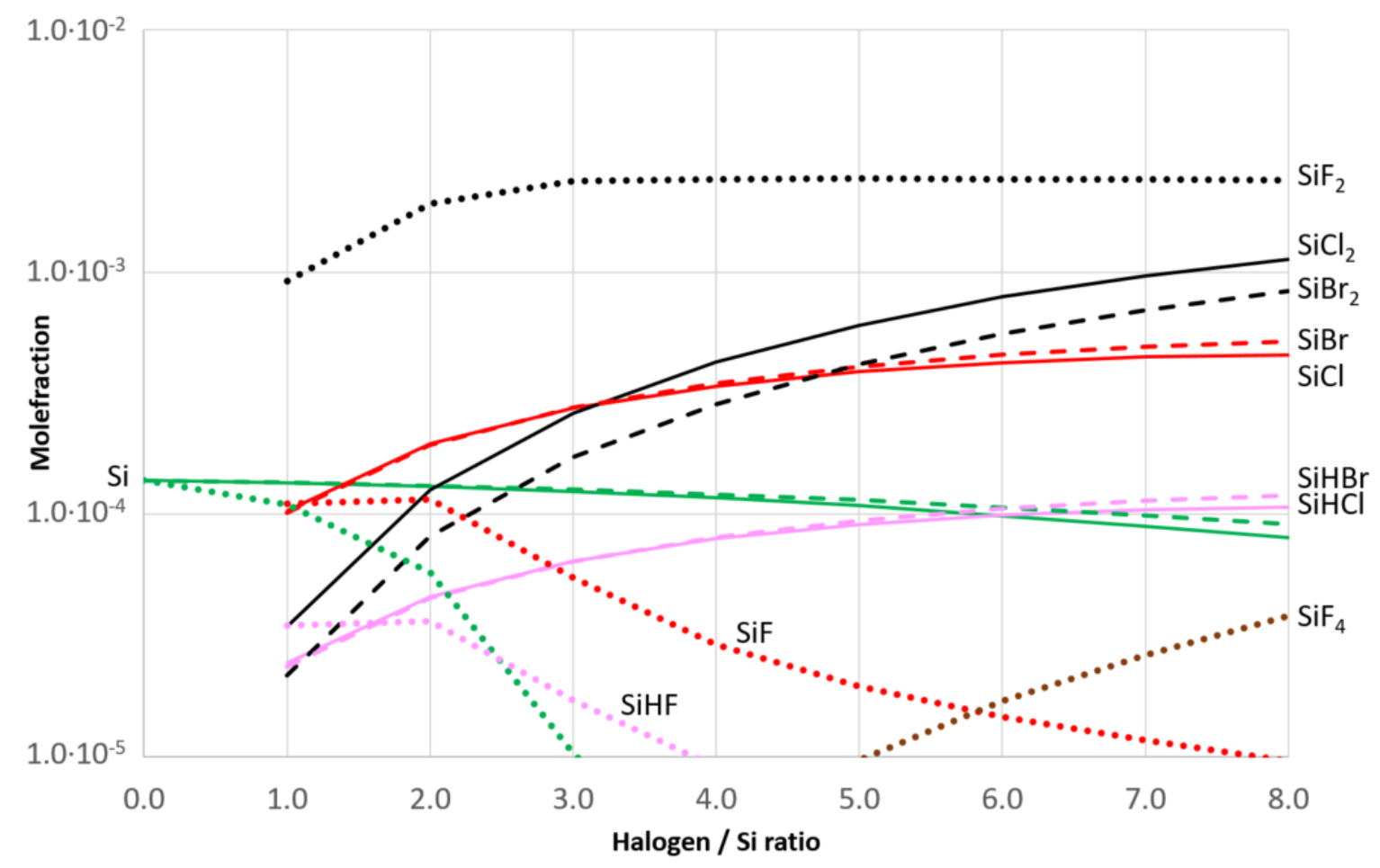

Fig. 2 Molefractions of halogenated silicon species at equilibrium when varying the X/Si ratio $\left(\mathrm{T}=1600^{\circ} \mathrm{C}, \mathrm{Si} / \mathrm{H}_{2}=0.25 \%, \mathrm{C} / \mathrm{Si}=1.0\right)$. Solid lines represent a chlorinated $\mathrm{CVD}$ chemistry, dashed lines a brominated CVD chemistry and dotted lines a fluorinated CVD chemistry. 